\title{
Ebeveynleri Çocuk Acile Getiren Nedenler: 4 Ylllık İzlem
}

\author{
Causes of Pediatric Emergency Department Applications of Parents: \\ 4 Years Follow-Up
}

\author{
Nazmi Mutlu Karakaş, Beril Özdemir, Serhat Kılıç, Özlem Akbulut \\ Başkent Üniversitesi Tıp Fakültesi Çocuk Sağlığı ve Hastalıkları Anabilim Dalı, Ankara, Türkiye
}

\begin{abstract}
Özet: Tüm acil servis başvuruların \%30’ unu oluşturan Çocuk Acil Servis başvuruları gerekli önlemlerin alınmasına rağmen hala yüksek oranını korumaya devam etmektedir. Sunulan hizmetin daha iyi ve bilimsel olması açısından acile servis verilerinin değerlendirilmesi oldukça önem taşımaktadır. Çalışmamızda ebeveynlerin çocuk acil servislerine başvurmasına neden olan şikâyetlerinin tespit edilmesi ve değerlendirilmesi amaçlanmıştır. Değerlendirmede 01.01.2014 - 31.12.2017 tarihleri arasında, Çocuk Acil Servisine başvurular esas alındı. Triyaj yapan sağlık personeli tarafından ebeveynin ilk ve önemli bulduğu şikayeti, hastanın yaşı, yatış, reçete ve sevk bilgileri kayıt altına alındı. 24 saat içerisinde tekrarlayan başvurular değerlendirmeye dışı bırakıldı. Başvuran 132654 hastanın \%52.8' i erkek ve \%47.2' si kızdı. Yaş dağılımlarına bakıldığında, yenidoğan döneminde \%2.1, 1 ay ile 2 yaş arasında \%34.5, 2 yaş ile 6 yaş arası \%31.2, 6 yaş ile 11 yaş arası $\% 19.9,11$ yaş ile 18 yaş arası ise \%12.3 olduğu görüldü. En sık başvuru sebebi; enfeksiyona ait nedenler (\%44.24) ağrı (\%17.8) ve gastrointestinal nedenler (\%14.5) olarak bulundu. Başvuran hastaların yarısına reçete ile ayaktan tedavi verilirken, $\% 1.5$ 'i servis ve yoğun bakım yatışlarının uygun görüldügü belirlendi. Çalışmamızda ebeveynlerin çocuklarını acil servise getiriş kaygılarının, ateş ve öksürük gibi enfeksiyon kaynaklı nedenler olduğu tespit edildi. Sonuçlar değerlendirildiğinde, alanında deneyimli sağlık çalıșanlarının ateș ve öksürük ile seyreden hastalıklar hakkında bilgi vermelerinin ebeveynlerin gereksiz kaygılarını azaltabileceğini ve bu şekilde acil servis başvurularını da azaltabileceği düşünüldü.
\end{abstract}

Anahtar Kelimeler: acil servis, yakınma, çocuk.

Abstract: Although there are several precautions, the number of applications to the Pediatric Emergency Department (PED) out of $30 \%$ of all applications still keeps its high rate. It is important to evaluate the emergency services' data in order to keep a good and scientific service. In this study, it was aimed to examine and evaluate the complaints that caused parents to apply to PED.Between 01.01.2014 and 31.12.2017, applications to PED were taken as basis. The first complaint of the parent which was considered to be most important; the patient's age; hospitalization, prescription and referral information were recorded by the triage medical staff. Repeated applications within 24 hours were not evaluated.Of the 132654 patients who applied, $52.8 \%$ were male and $47.2 \%$ were female. Among to the age distribution, $2.1 \%$ was in the newborn period, $34.5 \%$ was in between the age of 1 month to 2 years, $31.2 \%$ was in between 2 to 6 years, $19.9 \%$ was in between 6 to 11 years and $12.3 \%$ was in between 11 to 18 years old. When the distribution of causes was evaluated in the main group, the causes of infection $(44,24 \%)$ were the most common, followed by pain causes $(17,8 \%)$ and gastrointestinal causes $(14,5 \%)$. While half of the patients was prescribed as outpatient treatment, the pediatric service and intensive care hospitalization of $1.5 \%$ of the main group were found to be proper. In this study, it was observed that the reasons and the concerns for PED applications of the patients were the symptoms of infection such as fever or coughing. Upon the evaluation of the results, it can be considered that providing information to the parents about fever and cough by the experienced health workers may reduce their unnecessary concerns, leading to reduce number of PED applications.

Keywords: emergency department, complaint, child

ORCID ID of the authors: N.M.K. 0000-0003-4286-7086, B.Ö. 0000-0002-9646-9377, S.K. 0000-0003-3705-4312 Ö.A. 0000-0001-6372-7627

Received 19.10.2018

Accepted 05.12.2018

Online published 06.12 .2018

Correspondence: Nazmi Mutlu KARAKAŞ- Başkent Üniversitesi Tıp Fakültesi Çocuk Sağlığı ve Hastalıkları Anabilim Dalı, Ankara, Türkiye e-mail-drmutlukarakas@hotmail.com 


\section{Giriş}

Çocuk Acil Servisleri (ÇAS), tüm birimleri ve çalışanlarılyla 24 saat kesintisiz hizmet veren önemli bir hastane ünitesidir. Başvurulara etkin, hızlı ve doğru hizmet sorumluluğu içerisinde müdahale hedeflenmiş olsa da maalesef hasta, hasta yakını ve çalışan yönünden ruhsal geriliminin en üst seviyede olduğu bir ortama dönüşebilmektedir (1-2). Tüm ülkelerde olduğu gibi ülkemizde de acil servislerin acil müdahael gereksinimi olmayan hasta ve hasta yakınları tarafından yüksek oranda tercih edilmesi sorunu bilinmektedir. Başvuru sayısı arttıkça sağlık çalışanlarının gerçek acil olguların değerlendirilmesinde ve seçilmesinde, tedavi önceliklerini belirlenmesinde sıkıntılar doğabilmektedir (35). Türkiye'de Sağlık Bakanlığı 2017 verilerine göre ilk 9 ayda ÇAS'ne başvuru sayısı yaklaşı 296 milyon olduğu, başvurularda ilk sırayı \%25.9 ile acil tıp başvurularının oluşturduğu, ÇAS başvuruları ise on dördüncü sırada, tüm başvuruların \%2.61'si (yaklaşık 7.7 milyon başvuru) olduğu raporlanmıştır. Çocuk acil başvuruları sadece çocuk acil servisi olan hastanelerin bildirimi olduğundan, birinci sıradaki acil tıp başvurularının içinde de önemli bir kısım çocuk hastaların başvurusu olduğu düşünülebilir (6). Benzer şekilde Türkiye Çocuk Acil ve Yoğun Bakım Derneğinin 2008'deki bildirimine göre tüm acil başvurularının \%30' unu çocuk hastalar oluşturmaktadır (7). Amerika Birleşik Devletleri'nde ise acil servis başvurularının \%4-\%10'unun çocuk hastalar olduğu bildirilmiştir. Gelişmekte olan ülkelerdeki bildirimler ise tek merkez verilerini yansitan yayınlardır. Misır'dan yapılan tek merkezli çalışmada, bir yıl boyunca başvuran çocuk hasta sayıs1 43.668 iken, Tunus'ta yapılan tek merkezli çalışmada ise bir yıl boyunca yaklaşık 45.000 çocuk hasta başvurusu olduğu raporlanmıştır (8-9).

ÇAS' ine başvuruları etkileyen nedenler ilgili birçok çalışma bulunmaktadır. Genelde bu çalışmaların tanı dağılımı üzerinden olduğu, tanı haricinde ailenin çocuğun hangi durumundan kaygilanarak ÇAS' ine başvurduğunu değerlendirilmesinin de gerekli olduğu düşünülmüştür. ÇAS' lerinin uygun olmayan kullanım nedenlerinin değerlendirildiği çalışmalarda, hasta yakınlarının, anında hızlı sağlık hizmeti almak isteği, özellikle üçüncü basamak sağlik kuruluşlarında daha donanımlı laboratuvar hizmeti alma isteği ve acil servislerin birinci basamağa göre daha etkin ve yeterli yerler olduğunu düşünmeleri olduğu tespit edilmiştir $(2,10)$. Mali ve kişisel kaynakların etkin kullanılması, değerlendirmesi ve dağıtımında, çocuk acil servis kayıtlarının incelenmesi ve yorumlanmasıyla sağlanabilir. (11-13). Elde edilen sonuçların değerlendirilmesi sonucunda hasta ve hasta yakınlarının doğru bilgilendirilmesi, eğitilmesiyle bu uygunsuz başvuruların sayısı azaltılabileceği düşünülmektedir. Çalışmamızda, özel-vakıf üniversite özelliğindeki hastanemizin çocuk acil servisine başvuru sebeplerinin dağılımının değerlendirmesi amaçlanmıştır.

\section{Gereç ve Yöntem}

Etik onam, Başkent Üniversitesi Tıp ve Sağlık Bilimleri Araştırma Kurulu tarafindan onaylanan (Proje no: KA18/09) çalışmamız, 01.Ocak.2014 ile 31.Aral1k.2017 tarihleri arasında Başkent Üniversitesi Tıp Fakültesi Ankara Hastanesi Çocuk Acil Servisinde tanı ve tedavileri planlanan hastalarla yapıldı. Retrospektif yapılan çalışmamızda, triyaj yapan sağlık personeli tarafından hastay getiren kişinin ilk ve önemli bulduğu şikâyet dikkate alındı. Diğer şikâyetler çalışma dışı bırakıldı. Her bir başvuru için geliş nedeni olarak bir yakınma değerlendirildi. Şikâyetler ana başlık ve alt başlıklar halinde sinıflandırıldı. Hastaların demografik özellikleri (cinsiyet ve yaş), yapılan işlemler (reçete sayısı, sevk durumu ve yatış durumu) kayıt altına alındı. Yirmi dört saat içinde tekrar eden başvurular çalışmaya dahil edilmedi. Veriler, SPSS 20.0 programı ile analiz edildi ve kategorik değişkenler sayı (n) ve yüzde (\%) ile belirtildi.

\section{Bulgular}

Dört yıllık süre içerisinde ÇAS' ine başvuran hasta sayıs1 132654 olarak tespit edildi. Bu hastaların \%52.8' i erkek ve \%47.2' si kızdı. 
Yaş dağılımlarına bakıldığında, yenidoğan döneminde $\% 2.1,1$ ay ile 2 yaş arasında $\% 34.5,2$ yaş ile 6 yaş arası $\% 31,2,6$ yaş ile 11 yaş arası $\% 19.9,11$ yaş ile 18 yaş arası ise $\% 12.3$ olduğu görüldü. Nedenler dağılımı ana gruplar halinde değerlendirildiğinde, ebeveynler en sik enfeksiyon kaynakl1 nedenlerle (\%44.24) başvurduğu görüldü.
Bunu sırasıyla ağrı nedenleri (\%17.8) ve gastrointestinal nedenler (\%14.5) izledi. Genel durum bozukluğu $(\% 0.04)$ ve kanama $(\% 0.5)$ en nadir başvuru nedenleri olarak saptandi. Ailelerin acile başvurularının ana başlıklarının yıllara göre dağılımı tablo halinde verildi (Tablo 1).

Tablo 1. Ailelerin acile başvurularının ana başlıklarının yıllara göre dağılımı

\begin{tabular}{|c|c|c|c|c|c|c|c|c|c|c|}
\hline & 2014 & $\%$ & 2015 & $\%$ & 2016 & $\%$ & 2017 & $\%$ & Toplam & $\%$ \\
\hline Ağrı Nedenleri & 5927 & 18,41 & 5625 & 15,5 & 6051 & 18,61 & 5965 & 18,84 & 23568 & 17,8 \\
\hline Enfeksiyon Nedenleri & 15114 & 46,95 & 17392 & 47,92 & 13072 & 40,21 & 13125 & 41,45 & 58703 & 44,24 \\
\hline Gastrointestinal Sorunlar & 3972 & 12,34 & 5069 & 13,97 & 5211 & 16,03 & 4892 & 15,45 & 19144 & 14,5 \\
\hline Metabolik Sorunlar & 1022 & 3,17 & 916 & 2,52 & 964 & 2,97 & 722 & 2,28 & 3624 & 2,7 \\
\hline $\begin{array}{l}\text { Kardiyovasküler } \\
\text { Sorunlar }\end{array}$ & 254 & 0,79 & 322 & 0,89 & 301 & 0,93 & 288 & 0,91 & 1165 & 0,9 \\
\hline $\begin{array}{l}\text { Solunum Sistemi } \\
\text { Sorunları }\end{array}$ & 463 & 1,44 & 612 & 1,69 & 645 & 1,98 & 720 & 2,27 & 2440 & 1,8 \\
\hline Nörolojik Sorunlar & 245 & 0,76 & 314 & 0,87 & 236 & 0,73 & 201 & 0,63 & 996 & 0,7 \\
\hline Ortopedik Sorunlar & 3323 & 10,32 & 3948 & 10,87 & 3847 & 11,83 & 3851 & 12,16 & 14969 & 11,4 \\
\hline Görme İle İlgili Sorunlar & 499 & 1,55 & 466 & 1,28 & 329 & 1,01 & 319 & 1,01 & 1613 & 1,2 \\
\hline Ürolojik Sorunlar & 426 & 1,32 & 402 & 1,11 & 569 & 1,75 & 484 & 1,53 & 1881 & 1,4 \\
\hline Kanama Nedenleri & 212 & 0,66 & 185 & 0,51 & 171 & 0,53 & 162 & 0,51 & 730 & 0,5 \\
\hline Adli Vakalar & 427 & 1,34 & 437 & 1,2 & 457 & 1,41 & 583 & 1,84 & 1904 & 1,41 \\
\hline Alerjik Sorunlar & 296 & 0,92 & 572 & 1,58 & 643 & 1,98 & 349 & 1,1 & 1860 & 1,41 \\
\hline Genel Durum Bozukluğu & 10 & 0,03 & 31 & 0,09 & 11 & 0,03 & 5 & 0,02 & 57 & 0,04 \\
\hline Toplam & 32190 & 100 & 36291 & 100 & 32507 & 100 & 31666 & 100 & 132654 & 100 \\
\hline
\end{tabular}

Ebeveynlerin hastane başvurma nedenleri değerlendirildiğinde ateş (\%22.3), öksürük (\%16.4) ve bulant1-kusma (\%9.6) idi. Enfeksiyon kaynaklı nedenleri içinde de $\% 22.33$ ' ünü ateş en sık başvuruları olduğu görüldü. Ağrısı olan hastalarda en sık boğaz ağrıs1 (\%5.94) tespit edildi. Gastrointestinal sorunlarda ise bulant1-kusma $(\% 9,4)$ yakınması ön plandaydı. Metabolik sorunlarda ise huzursuzluk-emmeme $(\% 2,05)$ en s1k yakınma olarak saptandı. Nörolojik sorunlarda nöbet geçirme $(\% 0,28)$ ile kardiyovasküler sorunlar içinde göğüs ağrısı $(\% 0,66)$ en sik nedenlerdi. Solunum sistemi değerlendirmesinde yakınma olmasa da ebeveynlerin bronşit ve/veya bronşioliti $(\% 1,2)$ yakınma olarak söyledikleri görüldü. Ortopedik ve travmatik olaylarda en sik düşme $(\% 7,14)$, görme sorunlarında gözde kızarıklık-kaşıntı $(\% 0,99)$, ürolojik sorunlarda idrar yaparken yanma $(\% 1,12)$, kanama grubunda ise en s1k burun kanamas1 $(\% 0,45)$ ensık başvuru nedeni olarak tespit edildi. Adli vakalar grubunda ise en sık yanık vakaları gözlemlendi. Diğer yakınmalar grubunda ise en sik allerjik yakınmalar $(\% 0,76)$ saptandı. ÇAS' ine başvuruların genel dağılımında en s1k iki neden olarak tabloda verildi (Tablo 2). En sik acil başvuru 2015 y1lında olup, 2015 yılında gece poliklinik hizmetleri başlamış olsa da acile başvuru sayısında azalma olmadığı görüldü.

Acil servisten çıkış sonuçlarına göre 65617 $(\% 49,48)$ hastaya reçete yazıldığı, 63277 $(\% 47,7)$ hasta ise reçetesiz önerilerle gönderildiği, $1259(\% 0,59)$ hastaya servis yatış1 verildiği, $739(\% 0,55)$ hasta ise yoğun bakım yatışı (yenidoğan, pediatri ve pediatrik kardiyoloji/kalp-damar yoğun bakım) 
verildiği tespit edildi. 1709 hasta $(\% 1,29)$

belirlendi. Sadece 4 hasta acil serviste yakınları tarafindan ileri tetkik ve tedaviyi kardiyo-pulmoner arrest nedeniyle kaybedildi. kabul etmeme nedeniyle kendi istekleri ile ayrıldığ 1,49 hasta ise uygun yatı̧̧ yeri olmaması diğer merkezlere sevk edildiği ÇAS' ine başvuran çocukların sonlandırılma durumları tablo halinde verilmiştir (Tablo 3).

Tablo 2. Çocuk acil servise başvuru şikayetlerinin dağılımı grup içi en sık görülen iki neden

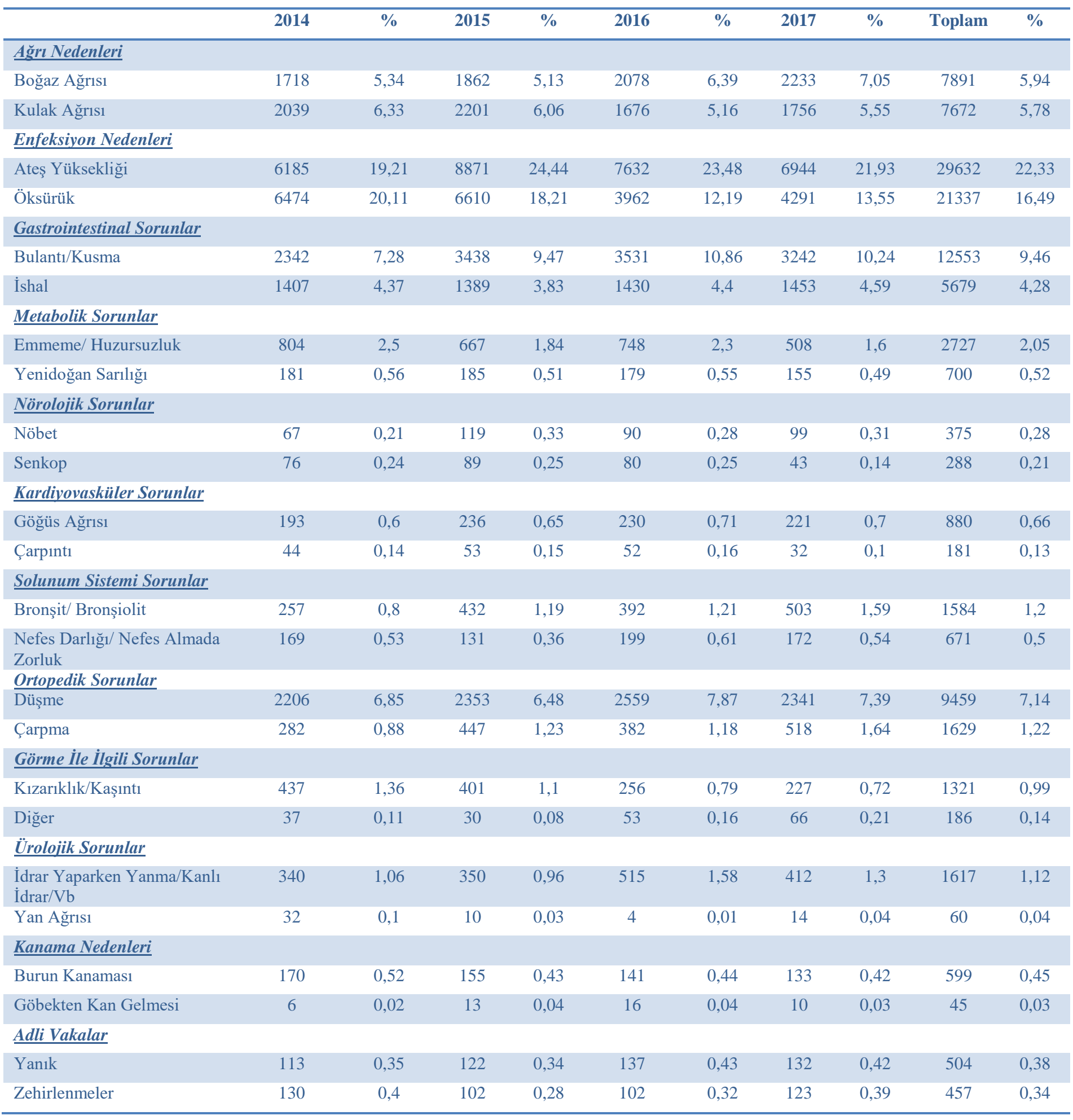




\begin{tabular}{lcccccccccc}
\hline Diğer Sorunlar & & & & & & & & \\
Alerjik Sorunlar & 145 & 0,45 & 313 & 0,87 & 385 & 1,18 & 155 & 0,5 & 998 & 0,76 \\
Yabanc1 Cisim Yutma & 64 & 0,2 & 114 & 0,31 & 107 & 0,34 & 78 & 0,25 & 363 & 0,27 \\
\hline
\end{tabular}

Tablo 3. Başvuran çocukların son durumları dağılımı

\begin{tabular}{lccccccccccc}
\hline & $\mathbf{2 0 1 4}$ & $\boldsymbol{\%}$ & $\mathbf{2 0 1 5}$ & $\boldsymbol{\%}$ & $\mathbf{2 0 1 6}$ & $\boldsymbol{\%}$ & $\mathbf{2 0 1 7}$ & \% & Toplam & \% \\
\hline Önerilerle gönderildi & 13820 & 42.94 & 20262 & 55.84 & 13879 & 42.7 & 15316 & 48.37 & 63277 & 47.7 \\
Reçete verildi & 17508 & 54.4 & 14965 & 41.23 & 17596 & 54.06 & 15548 & 49.1 & 65617 & 49.48 \\
Servis yatışı & 363 & 1.12 & 357 & 0.98 & 310 & 0.95 & 229 & 0.72 & 1259 & 0.95 \\
Yoğun bakım yatışı & 62 & 0.19 & 201 & 0.55 & 251 & 0.77 & 225 & 0.71 & 739 & 0.55 \\
Arrest (Exitus) & 1 & 0 & 0 & 0 & 0 & 0 & 3 & 0.01 & 4 & 0 \\
$\begin{array}{l}\text { İleri tetkik ve tedaviyi kabul } \\
\text { etmeme }\end{array}$ & 416 & 1.29 & 492 & 1.36 & 466 & 1.5 & 335 & 1.06 & 1709 & 1.29 \\
Başka merkeze sevk & & & & & & & & \\
Toplam & 20 & 0.06 & 14 & 0.04 & 5 & 0.02 & 10 & 0.03 & 49 & 0.03 \\
\hline
\end{tabular}

\section{Tartışma}

Son yıllarda hasta yakınlarının çabuk sonuç alma isteği ÇAS başvurularının artmasını kaçınılmaz hale getirmektedir. Ancak çoğu ÇAS' nde sabit ve sınırlı fiziki şartlar ve personel ile bu talebin karşılanmaya çalışılmasında zorluklar yaşanmaktadır. Çocuk Acil Servislerinin verilerinin belli aralıklarla değerlendirilmesinin, verilen sağlık hizmetinin dağılımının, kalitesinin ve yeniden düzenlenmesinde oldukça değerli olduğu bilinmektedir. Ankara ili dahilinde birçok üniversite, eğitim-araştırma hastanesi ve devlet hastanesinde ÇAS' leri bulunmasına ve özellikle gece poliklinik hizmetlerinin eklenmesine rağmen daha önceki çalışmalarda da gösterildiği gibi en sik başvuru nedenlerinin ve tanılarının çoğunluğunun çalışmamızda da benzer şekilde görüldüğü gibi genel polikliniklerde yönetilebilecek hastalar olduğu bizim çalışmamızda da görülmüştür $\quad(1,14-16) . \quad \mathrm{Bu}$ kanıya varılmasındaki en önemli neden ise, \%47,7 oranında reçetesiz, her hangi bir işlem yapılmadan önerilerle gönderilen hasta sayısidır.

Hastanemizde, 2015 y1lından itibaren pediatri uzman-öğretim görevlisi ve öğretim üyesi düzeyinde gece poliklinik hizmetleri başlatılmıştır. Fakat bu yıldan itibaren çocuk acile başvuru sayısında azalma olmadığı görülmüştür. 2016 y1lından itibaren, gündüz çocuk acil servisinin yanında kurulan ve randevusuz hizmet veren poliklinik açılmasına rağmen, başvuru sayısında azalma olmadığ görülmüştür. Boran ve ark. çalışmalarına benzer şekilde değerlendirmemizde, yoğunluk özellikle gündüz çalışma saatleri ve öğle tatili saati ile akşam saat 7 ile gece yarısı 12 arasında yaşanmaktadır. Bunun ana nedeni, özellikle çalışan ebeveynlerin gündüz polikliniklere gelemeyişi ve iş çıkışı çocukla buluşup acil servise başvuruları olduğu düşünülmektedir. Bununla birlikte başvuran hastaların yaş dağılımı incelendiğinde de, 1 ay ile 6 yaş arasının en sık başvuru yaşı olduğu görülmüsşür. Türkiye ve İtalya'dan yapılan ek merkezli çalışmalarda ve Amerika Birleşik Devlerinden çok merkezli çalışmada da çalışmamıza benzer olarak 1 ay ile 6 yaş arası başvuruların sık olduğu görülmüştür. Benzer olarak bu üç çalışmada, çocuk acil servis başvurularında en sık alınan tanı akut farenjit ve soğuk algınlığı iken, çalışmamızda tanılar ve ICD kodlar dikkate alınmamakla birlikte benzer şekilde en sık başvuru nedenlerinin bu tanılara işaret eden ateş ve öksürük yakınmaları olduğu saptanmıştır (17-19). Bazaraa ve ark.'larının 1441 hasta üzerindeki 
çalışmasında ise en sık başvuru nedenleri sırasıyla solunum sıkıntısı, hışı1tı, konvülzyon, solukluk ve ateş olduğu bildirilmiştir (8). Solunum sıkıntısı ve hışıltı $\% 41,7$ oranında başvuru sıklığına sahipken, birçok çalışmada bu oranın\%29-40 arasında değiştiği saptanmıştır $\quad(8-9,20-21)$ Çalışmamızda ise toplam \%18,3 hastanın solunum sistemini ilgilendiren yakınmalarla başvurduğu görülmüştür. Solunum sistemi sorunlarında "bronşit" ve "bronşiolit" ifadelerinin olmasının sebebi, ebeveynlerin bassvuru anında israrla bu kelimeleri kullanmaları ve bu terminolojiyi bir yakınma olarak değerlendirdikleri düşünülmüştür.

Ebeveynlerin hastaneye geliş nedenleri ile ilgili sınırlı sayıda çalışma bulunmaktadır. Çalışmamızda çocukların hastanemize başvurularının en sık nedeni ateş yakınması iken Bazaraa ve ark. çalıșmasında bu sorun beșinci sırada ve \%8 oranında raporlanmıștır (8). Çalışmamıza benzer olarak Ljaz ve ark. Pakistan'dan yaptı̆̆ 1 tek merkezli çalışmada ÇAS' e başvuran hastaları triyaj ile değerlendirmiştir. $\mathrm{Bu}$ değerlendirme sonucunda ÇAS' en sık başvuru sebebi olarak ateş $(\% 15,6)$ olduğu saptanmıştır. Aynı çalışmada triyaj sonrası polikliniklere yönlendirilen hastaların değerlendirmesinde ise benzer şekilde en sık yakınmanın ateş olduğu görülmüştür. Ljaz ve ark'nın çalışmasında ateşten sonra en sik başvuru nedenleri ishal-kusma $(\% 14,1)$ ve solunumsal problemler $(\% 11,3)$ olarak belirlenmiştir $(22)$. Çalışmamızda ishal-kusma-bulantı \%13,74 oranında saptanmıştır. Ljaz ve ark. daha önceki verilere göre ishal başvuru sıklığının azaldığını raporlamışlardır

Çalışmamızda yıllar içerisinde değişim göstermediği, fakat 5 yaş altı çocuk ölümlerinde ön siralarda yer alan ishalin, diğer çalışmalarda olduğu gibi daha nadir görülen bir geliş nedeni olduğu görülmüştür.

Boran ve ark (15) ile Ontürk ve ark. (23) zehirlenme oranını sirasiyla \%1.4 ile \%1.8 saptamışken, çalışmamızda zehirlenme başvuruları toplam başvurunun $\% 0.34$ 'ü olduğu ve düşük olduğu görüldü. Servise yatış oranları değerlendirildiğinde Boran ve ark. (14) \%4.1, Anıl ve ark. (1) \%3,5 yatış oranı tespit etmişken çalışmamızda, bu oran daha düşük (\%1.5) saptand. Bunun nedeninin genel poliklinik ve yandal polikliniklerinin daha fazla yatış yapması ile 112 acil hizmetlerinin hastaları öncelikle devlet üniversite ve devlet hastanelerine yönlenmelerinden kaynaklandığı düşünüldü. Yatak sayımızın azlığının, acil servis ve acil yatışlarda ücret alınmasa da ailelerde ücret farkı çıkabilir korkusunun da yatış oranını azaltmada etkili olabileceğini düşündük.

Benzer şekilde Anıl ve ark. çalışmasında, çocuk acil servis hizmetlerinden yoğunluğu, özellikle acildeki hastalardan katk1 pay1 alınmaması, çalışan ebeveynlerin akşam iş çıkışı gelme istekleri ve acil servis hizmetlerinin, normal poliklinik hizmetlerine göre daha hızlı olmasından dolayı olduğunu düşünmüşlerdir (1). Çoğu hastane gibi, bizim hastanemizde de, bu durumu aşmak için önceleri gece poliklinik hizmetleri başlatılmıștı. Gece poliklinik hizmetleri tam dolu olmasına rağmen acil başvuruda azalma olmadığ1 görülmüştür. Bununla birlikte, ailelerin özellikle gece poliklinik hizmetlerinin bittiği akşam saat $10^{\prime} \mathrm{u}$ bekledikleri, o saatten sonra acile başvuru sayısının arttığı görülmüştür. Gündüz de, acilin hemen yanında, gündüz polikinik hizmetleri verilmesi başlanmış olup, poliklinikte tüm gün devamlı hasta bakılmasına rağmen gene de acil başvuru sayısı azalmadığ1 görülmüştür.

Anıl ve ark. belirttiği çözüm önerilerinde, halkın bilgilendirilmesi, çocuk acil servislerinin koşullarının iyileştirilmesi, çocuk travma merkezlerinin kurulması ve personel dağılımının katkıs1 büyük olacağ1 düşünülmektedir(1). Bunlara ek olarak, laboratuvar hizmetlerinin ve sonuçlarının seçilmiş öncelikli olgularda gündüz poliklinik şartlarında da iyileştirilmesi, radyolojik tetkiklerin de bener şekilde hılandırılması sürece katk1 sağlayabilecektir. Ayrıca başvuruların beşte birini oluşturan "ateş" hakkında sağlık çalışanlarının aileleri doğru bilgilendirme yapmas1 ve hasta ile bakım verene neler yapacağını anlatması başvuru sayısını azaltabileceği düşünülmektedir.

Sağlık Bakanlığı, Çocuk Acil ve Yoğun Bakım Derneği Önerileri ile dünya da acile 
başvuru nedenleri genelde sayı üzerinden verilmiş olup, ayrıca bu dağılım genelde tanı ve ICD-10 kodu üzerinden yapıldığ 1 görülmektedir. Tunus, Pakistan ve Misir çalışmalarında hastaların geliş nedenlerini ayırmış fakat hasta sayılarının az olduğu görülmüş̧ür. Çalışmamızın önemi vaka sayımızın fazlalığıdır ve direk başvuru yakınmasına odaklanmış olmasıdır. Çalışmamızda, ICD-10 kodu üzerinden bir dağılım yapılmamıştır.

Çalışmamızın kısıtllılıkları ise, sabit bir triyaj sağlık personeli tarafından yakınmaların

\section{KAYNAKLAR}

1. Anıl M, Anıl BA, Köse E, Akbay S, Helvac M, Aksu N. Bir Eğitim ve Araştırma Hastanesi Çocuk Acil Servisi' ne Başvuran Hastaların Değerlendirilmesi. J Pedatr Emerg Intens Care Med 2014; 2: 65-71

2. Edirne $\mathrm{T}$, Edirne $\mathrm{Y}$, Atmaca B, Keskin $\mathrm{S}$ Yüzüncü Yıl üniversitesi Tıp Fakültesi Acil Servis Hastalarının Özellikleri. Van Tip Dergisi 2008; 15: 107-111

3. Afillalo J, Marinovich A, Afilalo M, Colacone A, Leger $R$, Unger $B$ et al. Nonurgent emergency department patient characteristics and barriers to primary care. Acad Emerg Med. 2004; 11: 1302-10

4. Bezzina AJ, Smith PB, Cromwll D, Eagar K. Primary care patients in the emergency department: Who are they? A review of the definition of the "primary care patient" in the emergency department. Emerg ed Australas. 2005; 17: 472-9

5. Coleman P, Irons R, Nicholl J. Will alternative immediate care services reduce demands for non-urgent treatment at accident and emergency? Emerg Med J. 2001; 18: 482-7

6. "Her branşta ilk 100 hastane" 2017 yılı OcakEkim Dönemi Poliklinik, Yatış, Yoğun Bakım ve Acil Servis İstatistikleri, T.C. Sağlık Bakanlığ 1 Kamu Hastaneleri Genel Müdürlüğü, Ankara. Aralık, 2017

7. Türkiye'de ve Dünya'da Çocuk Acil Tip Hizmetleri Mevcut Durum ve Öneriler. Çocuk Acil Tip ve Yoğun Bakım Derneği, İstanbul. 2008

8. Bazaraa HM, El Houchi S, Rady HI. Profile of patients visiting the Pediatric Emergency Service in an Egyptian University Hospital. Pediatr Emerg Care 2012; 28:148-152.

9. Matoussi N, Fitouri Z, Maaroufi N, Bericche I, Ben Bechir S. Epidemiologic profile and management pediatric medical emergencies consultants of Tunusian child's hospital. Tunis Med 2007; 85: 843-8. alınmamış olmasıdır. Asıl amacımız geliş nedenleri değerlendirilmek istense de gidiş tanıları ve hastaların başka merkezlere aynı şikâyetlerle başvurup başvurmadığının öğrenilmemesi de ek bir kısitlılık olarak düşünülebilir. ICD-10 koduna göre tan1 dağılımının olmaması kısıtlılık gibi gözükse de bu çalıșmanın amacı ailelerin başvuru yakınmalarıdır.

Teşekkür: Çocuk Acil Servis Hemşirelerine verilerin elde edilmesindeki katkılarından dolayı teşekkür ederiz.

10. Pereira S, Oliveira e Silva A, Quintas M, Almeida J, Marujo C et al. Appropiriateness of emergency department visits in a Portuguese university hospital. Ann Emerg Med. 2001; 37:580-6

11. Cimrin AH, Topacoglu H, Karcioglu O, Ozsarac M, Ayrik C. A model of training in basic life support skills of emergency medicine residents. Adv Ther 2005, 22: 10-8.

12. Lynn SG, Kellermann AL. Critical desicion making: Managing the emergency deparment in an over crowded hospital. Ann Emerg Med 1991; 20: 287-92.

13. American College of Emergency Medicine. Measures to deal with emergency department over crowding. Ann Emerg Med 1996; 3: 3058.

14. Boran P, Tokuç G, Büyükkalfa DÇ, Taşkın B, Pişgin B. Çocuk Acil Servisine Başvuran Vakaların Değerlendirilmesi. Çocuk Dergisi 2008; 8: 114-6

15. Derinöz O, Tunaoğlu FS. Çocuk acil gözlem birimlerinin çocuk hastalar için kullanımı: bir üniversite hastanesinin izlenimleri. Türk Ped Arş 2007; 42: 61-64.

16. O'Brien GM, Shapiro MJ, Woolard RW, O'Sullivan PS, Stein MD. Inappropriate emergency department use: a comparison of three methodologies for identification. Acad Emerg Med 1996; 3: 252-7

17. Giacalone T, Vanelli M, Zinelli C, Ndongko A, Ndaka J, Casadei A, Nicoli D. One year experience at the Emergency Unit of the Children's Hospital of Parma. Acta Bio Med 2003; 74: 34-7.

18. Kilıçaslan İ, Bozan H, Oktay C, Göksu E. Türkiye'de acil servise başvuran hastaların demografik özellikleri. Türkiye Acil Tip Dergisi 2005; 5: 5-13.

19. Alpern ER, Stanley RM, Gorelick MH, Donaldson A, Knight S,Teach SC, et al.Pediatric Emergency Care Applied Research Network. Epidemiology of pediatric 
emergency medicine research network: the PECARN Core Data Project. Pediatr Emerg Care. 2006; 22:689-99

20. Kouki R, Mokdad M, Kouzena N, Sayari S. Evaluation of the activity of the emergency department Nefza disrict hospital. Tunis Med. 2006; 84: 747-50.

21. Matoussi N, Fitouri Z, Maaroufi N, Bericche I, Ben Bechir S. Epidemiologic profile and management pediatric medical emergencies consultants of Tunusian child's hospital. Tunis Med 2007; 85: 843-48.

22. Ijaz N, Strehlow M, Wang NE, Pirrotta E, Tariq A, Mahmood N, Mahadevan S. Epidemiology of patients presenting to a pediatric emergency department in Karachi, Pakistan. BMC Emergency Medicine 2018: 1822.

23. Ontürk AY, Uçar B. Eskişehir bölgesinde çocukluk çağı zehirlenmelerinin retrospektif değerlendirilmesi. Çocuk Sağliğl ve Hastalıkları Dergisi 2003; 46:103-13. 